\title{
Spatial distribution of vegetation and the influencing factors in Qaidam Basin based on NDVI
}

\author{
WenBin $Z \mathrm{HU}^{1,2}$, AiFeng $\mathrm{LV}^{1}$, ShaoFeng $\mathrm{JIA}^{1^{*}}$ \\ ${ }^{1}$ Institute of Geographical Sciences and Natural Resources Research, CAS, Beijing 100101, China; \\ ${ }^{2}$ Graduate University of Chinese Academy of Sciences, Beijing 100039, China
}

\begin{abstract}
The spatial distribution of vegetation in Qaidam Basin was analyzed using GIMMS (Global Inventory Modeling and Mapping Studies) / NDVI (Normalized Difference Vegetation Index) data set from January 1982 to December 2006. Based on the data of precipitation, terrain, stream systems, land use and the map of vegetation distribution in Qaidam Basin, we studied the factors influencing the spatial distribution of vegetation. The results showed that the vegetation was generally low in Qaidam Basin and there was a clear semi-ring structure from southeast to northwest. In some areas, the existence of rivers, lakes and spring belts turned this semi-ring structure into a non-continuous state and formed distinct bright spots and continuous linear features. There were four main factors that affected the spatial distribution of vegetation coverage in Qaidam Basin, i.e., precipitation, hydrological conditions, altitude and human activities. Precipitation and altitude have a correlation and determine the basic pattern of vegetation distribution in Qaidam Basin. The impacts of hydrological conditions and human activities were mainly embodied in partial areas, and often broke the pattern of vegetation distribution dominated by precipitation and altitude.
\end{abstract}

Keywords: NDVI; vegetation coverage; spatial differentiation; hydrological conditions; Qaidam Basin

\section{Introduction}

Vegetation, as a natural bridge linking soil, air, water and other environmental factors, is the most distinctive symbol of the ecological environment (Chen et al., 1998; Cui et al., 2009). Remote sensing technology with the features of objective, real-time and macroscopic imaging, has special advantages in dynamic detection of vegetation over large areas (Chu et al., 2007). Among various parameters reflecting surface features, Normalized Difference Vegetation Index (NDVI), which is very sensitive to the productivity and activity of vegetation, is considered as a good indicator of vegetation (Zhao, 2003; Zhang et al., 2005; Zhao et al., 2008). There are several NDVI datasets derived from different satellites, but the dataset derived from AVHRR (Advanced Very High Resolution Radiometer) data of NOAA (National Oceanic and Atmospheric Administration) satellite, because of its long-time series, is used most widely in the research of terrestrial ecosystems (Justice and Hiernaux, 1983; Tucker et al., 1985; Yang et al., 1998; Zheng et al., 2004).
There have been a lot of studies on ecology using NDVI (Nicholson and Farrar, 1994; Rasmusen, 1998; Richard and Poccard, 1998; Ma et al., 2003; Cheng et al., 2008; Han et al., 2008). However, the previous studies focused mainly on the dynamic change of vegetation and the relationship between vegetation and climate. The multi-year average of NDVI reflects the normal state of vegetation coverage over a certain area. Therefore, it is another important application of NDVI to study the pattern of vegetation distribution and its influencing factors by the use of multi-year average NDVI.

Qaidam Basin is a huge basin on the northern edge of the Tibetan Plateau. Due to its special geographical location and climatic characteristics, the vertical and spatial differentiation of vegetation is very obvious(Fan and Zhao, 2008). So, Qaidam Basin is an ideal area for the application of NDVI. Different researchers have studied the ecological environment of Qaidam Basin, which provided important information

Received 2010-11-08, accepted 2010-12-29 doi: 10.3724/SP.J.1227.2011.00085

* Corresponding author: ShaoFeng JIA (E-mail: jiasf@igsnrr.ac.cn) 
to the development and protection of Qaidam Basin (Ren, 2007; Ma et al., 2008; Li et al., 2009). However, the remote sensing data used in these studies are only limited to one year or a particular period, which has certain randomness and can not effectively represent the normal state of vegetation distribution. What's more, most of these studies focused mainly on the macroscopic analysis of vegetation distribution and lacked further study on the influencing factors of vegetation distribution. It is of great significance to study the spatial distribution of vegetation and its influencing factors by the use of a long-time series of NDVI data in order to expand the application of NDVI and to protect the ecological environment of Qaidam Basin.

\section{Study areas}

Qaidam Basin is a huge basin on the northern edge of the Tibetan Plateau, with an area of $275,000 \mathrm{~km}^{2}$ (Liu, 2000 ), and is located at the range of $35^{\circ} 00^{\prime}-39^{\circ} 20^{\prime} \mathrm{N}$, $90^{\circ} 16^{\prime}-99^{\circ} 16^{\prime} \mathrm{E}$. Qaidam Basin is surrounded by a series of mountains such as Altun Mountains, Kunlun Mountains and Qilian Mountains. The altitude of Qaidam Basin ranges from 2,676 $\mathrm{m}$ to $6,860 \mathrm{~m}$. The climate of Qaidam Basin is characterized by low, unevenly distributed precipitation and high radiation intensity. The average annual temperature ranges from $1.2^{\circ} \mathrm{C}$ to $4.3^{\circ} \mathrm{C}$, and the average annual precipitation decreases gradually from southeast to northwest while the overall precipitation is below $300 \mathrm{~mm}$ (Zhao et al., 2009). Therefore, Qaidam Basin is a typical arid and semi-arid area. The average vegetation coverage of Qaidam Basin is less than 5\% and the rate of forest coverage is only $0.84 \%$ (Yu et al., 2007).

In the interior of Qaidam Basin salt crust land and salt lake are developed, while in the northwest erosion dunes, deserts and gobi are widely distributed. The areas of high altitude in Kunlun and Qilian mountains are covered by snow, glacier, bare rock and alpine desert almost without vegetation coverage. There are nine types of vegetation in Qaidam Basin (Liu, 2000). Among them, in the areas around inland rivers, lakes and alluvial fans, the vegetation covers are relatively high. The growth of forest is limited greatly and only distributed in the sunny slope of the mountains. In the east of the basin, coniferous forest is distributed.
Shrub vegetation is mainly developed in valleys and riversides in the middle and lower reaches of the large rivers, and the coverage of vegetation is relatively high. In general, Qaidam Basin is dominated by desert vegetation. It is mainly scattered in the gobi and gravel zone of Altun and Kunlun mountains and some small basins such as Chahanwusu Basin, Delingha Basin, Dachaidan Basin, Xiaochaida Basin and Haima Basin. Grassland vegetation is the main vegetation type of temperate semi-arid areas, which includes desert and alpine grasslands in Qaidam Basin. Desert grassland is mainly distributed in the lower mountains, and alpine grassland is mainly scattered in the gullies and basins of Qilian Mountains, Kunlun Mountains and other mountains in the southeast of Qaidam Basin. The meadow vegetation of Qaidam Basin can be divided into salt and alpine meadows. Salt meadow is mainly located in the low land and the beaches of some lakes and rivers in the interior of the basin, and alpine meadow is mainly distributed in the high altitude areas of Qilian and Kunlun mountains. The coverage of vegetation is very low on the mountains where the altitude is higher than the areas where alpine meadow distributed. Among them, the area of highest altitude is distributed by vegetation of rock-flowing hillside and the cushion vegetation which is developed between sparse vegetation in high mountain and alpine meadow. The vegetation is in patch distributed.

\section{Materials and methods}

\subsection{NDVI dataset}

The vegetation index adopted in this study is NOAA/AVHRR-NDVI delivered by GIMMS. The spatial resolution is $8 \mathrm{~km} \times 8 \mathrm{~km}$ and time span ranges from January 1982 to December 2006. This NDVI dataset eliminated the effect of volcanic eruptions, solar elevation angle and the sensor changes over time, and has been widely used in vegetation studies on large and global scales (Guo et al., 2007). The original NDVI data provided by GIMMS ranges from $-10,000$ to 10,000 . Standard NDVI data ranging from -1 to 1 was obtained after conversion. In addition, when studying the influencing factors of vegetation distribution in Qaidam Basin, the maps of vegetation distribution, the data of topography, stream systems, land use and the isohyets of Qaidam Basin were also used. 


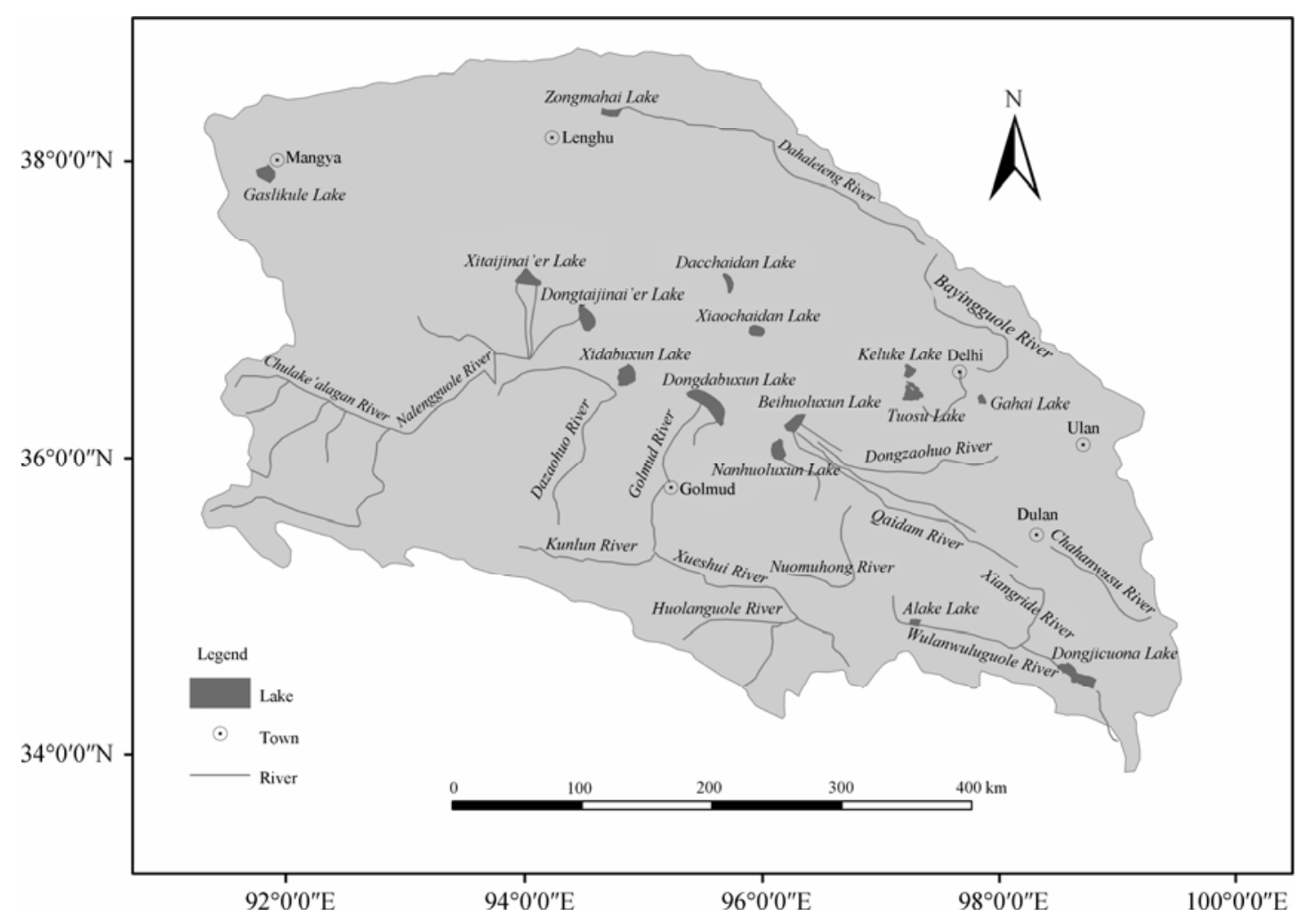

Fig. 1 Map of Qaidam Basin

\subsection{Methods}

Maximum Value Composites (MVC) method has been widely used in the application of NDVI data, which calculates the maximum NDVI of each pixel for every month to further eliminate the interference of cloud, atmosphere and solar elevation angle (Hope et al., 2003; Stow et al., 2004; Song and Ma, 2007). Since the vegetation coverage of Qaidam Basin changes greatly during a year, in order to further highlight the vegetation information of the study area, we extended the application of MVC method and calculated the annual maximum NDVI of each year $M_{N D V I}$. The formula is as follows:

$$
M_{N D V I i}=\max _{j=1}^{24} I_{N D V I_{i j}} .
$$

Where $M_{N D V I}$ is the annual maximum NDVI of $i$ year; $I_{N D V I j}$ is the NDVI of $j$ month in $i$ year. $M_{N D V i}$ represents the vegetation information in most abundant period within one year. To reflect the normal state of vegetation distribution in Qaidam Basin, the average of $M_{N D V I i}$ from 1982 to 2006 was calculated and the average annual maximum NDVI
( $\overline{M_{N D V I}}$ ) was used to study the distribution of vegetation in Qaidam Basin. The formula is as follows:

$$
\overline{M_{N D V I}}=\frac{1}{n} \sum_{i=1}^{n} M_{N D V I} \text {. }
$$

Where $\overline{M_{N D V I}}$ is the average annual maximum NDVI; $M_{N D V I}$ is the annual maximum NDVI of $i$ year; $n$ is 25 .

\section{Results and discussion}

\subsection{The spatial distribution of vegetation in Qai- dam Basin}

Figure 2 shows the spatial distribution of $\overline{M_{N D V I}}$ in Qaidam Basin. The vegetation distribution of Qaidam Basin has the following characteristics:

(1) The value of $\overline{M_{N D V I}}$ ranges from 0.0326 to 0.5837 , and the average is only 0.1404 . Overall the rate of vegetation coverage in Qaidam Basin is low.

(2) The distribution of vegetation varied greatly over the areas and has a clear semi-ring structure from southeast to northwest. In the center of the basin, the 
distribution of vegetation is a dustpan-shaped, and the opening of the dustpan is toward the northwest. Generally, the center of the basin is mainly composed by residual hills of wind erosion, sand dunes and salt crust land, and there is no vegetation in these areas. Outside the center, the distribution of vegetation has a clear semi-ring structure, and the opening of the semi-ring structure is also toward the northwest. In order to illustrate this semi-ring structure quantitatively, the values of $\overline{M_{N D V I}}$ in Qaidam Basin were divided into six levels, $0-0.1,0.1-0.2,0.2-0.3$, $0.3-0.4,0.4-0.5$, and $0.5-0.6$ (Fig. 3). Then the area and type of vegetation for each level were analyzed, respectively (Table 1).

As shown in Fig. 2, Fig. 3 and Table 1, the pixels with high $\overline{M_{N D V I}}$ values are mainly distributed in the southeast of the basin, which constitutes the outer layer of the semi-ring structure. In view of natural boundary, the outer layer is surrounded by Haerke Mountains, Zongwulong Mountains and Tanggewula Mountains. The $\overline{M_{N D V I}}$ value of this layer ranges from 0.2 to 0.6 , which mainly consisted of the levels 3 , 4 and 5. The level 6 is limited to the southeast corner of the basin, and the vegetation types are mainly grassland, shrub, forest and various meadows. The middle layer mainly consisted of the level 2 , and the $\overline{M_{N D V I}}$ values are between 0.1 and 0.2 . Overall, the middle layer is mainly composed of Qilian Mountains, Kunlun Mountains and the interior of outer layer, and the types are mainly cushion vegetation, alpine sparse vegetation and desert vegetation.

The inner layer of the semi-ring structure is constituted by the level 1, which is located in the center and northwest of the basin. Overall the $\overline{M_{N D V I}}$ value of inner layer is below 0.1. According to the interpretation of NDVI, vegetation is not distributed generally in the inner layer of the basin where $\overline{M_{N D V I}}$ value is below 0.1. To further illustrate the vegetation distribution of this layer, the maximum value of $M_{N D V I i}$ (Fig. 4) was calculated. The formula is as follows:

$$
M_{N D V I}=\max _{i=1}^{25} M_{N D V I i} .
$$

Where $M_{N D V I}$ is the maximum of $M_{N D V I i}$ within 25 years; $M_{N D V I i}$ is the annual maximum NDVI in $i$ year. In the areas where the value of $M_{N D V I}$ is below 0.1 , no vegetation is distributed within the 25 years (Fig. 4). By overlay analyzing Fig. 3 and Fig. 4, the inner layer was divided into two sub-areas. The sub-area 1 represents the areas of bare soil and no vegetation, while sub-area 2 represents the areas of main desert vegetation in wet year.

Table 1 Classification of $\overline{M_{N D V I}}$ in Qaidam Basin

\begin{tabular}{|c|c|c|c|c|}
\hline Layer & Level & $\begin{array}{c}\text { Area } \\
\left(10^{4} \mathrm{~km}^{2}\right)\end{array}$ & $\begin{array}{c}\text { Percentage of } \\
\text { area }(\%)\end{array}$ & Vegetation type \\
\hline \multirow{4}{*}{$\begin{array}{l}\text { Outer } \\
\text { layer }\end{array}$} & $6(>0.5)$ & 0.12 & 0.42 & \multirow{4}{*}{$\begin{array}{l}\text { Grassland, shrub, } \\
\text { forest and mead- } \\
\text { ows }\end{array}$} \\
\hline & $5(0.4-0.5)$ & 0.58 & 2.11 & \\
\hline & $4(0.3-0.4)$ & 1.33 & 4.83 & \\
\hline & $3(0.2-0.3)$ & 3.84 & 13.96 & \\
\hline $\begin{array}{l}\text { Middle } \\
\text { layer }\end{array}$ & $2(0.1-0.2)$ & 8.77 & 31.91 & $\begin{array}{l}\text { Alpine sparse } \\
\text { vegetation and } \\
\text { desert vegetation }\end{array}$ \\
\hline $\begin{array}{l}\text { Inner } \\
\text { layer }\end{array}$ & $1(<0.1)$ & 12.86 & 46.77 & $\begin{array}{l}\text { Salt crust, } \\
\text { wind-erosive dune } \\
\text { and desert }\end{array}$ \\
\hline Total & & 27.50 & 100 & \\
\hline
\end{tabular}

(3) Local non-zonal vegetation distribution breaks the overall vegetation distribution pattern of semi-ring structure. In partial areas (mainly the outflow zone of groundwater in the interior of the basin and Xiangride Oasis), as the existence of rivers, lakes and groundwater outflow, the moisture condition is better than other areas, so some non-zonal vegetations are developed such as reed, kalidium and other meadows. This makes the semi-ring structure present a non-continuous state. For example, the $\overline{M_{N D V I}}$ values of these areas are significantly higher than that of surrounding areas, and forms some distinct bright spots and continuous linear features. The most typical phenomenon is that there are several distinct bright spots in the wetlands and continuous linear feature in the spring overflow areas in the central and southern parts of the basin. These bright spots have a ring structure and the values of $\overline{M_{N D V I}}$ decreased with the increase of the distance from these water bodies. In the inner layer of the semi-ring, because the amount of water body is small, the distribution of non-zonal vegetation is relatively simple, but in the southeast of the basin, the interaction of various water bodies makes it relatively complex. 


\subsection{Influencing factors of vegetation distribution}

4.2.1 The relationship between vegetation distribution and precipitation

Figure 5 is the overlay map of Fig. 3 and isohyets in Qaidam Basin. Without the impact of rivers, lakes and groundwater outflow, the spatial distribution pattern of $\overline{M_{N D V I}}$ is almost consistent with the distribution pattern of precipitation, which is decreased from southeast to northwest. Specifically, except for the Xiangride Oasis, the boundary between inner and middle layers of vegetation distribution is consistent with the $100 \mathrm{~mm}$ rainfall contour and the boundary between middle and outer layers is almost entirely consistent with the $150 \mathrm{~mm}$ rainfall contour. The dividing line of two sub-areas in the inner layer, however, is different between the north and south of Tuosu Lake. To the north of Tuosu Lake $50 \mathrm{~mm}$ rainfall contour forms the dividing line of two sub-areas, while to the south 25 $\mathrm{mm}$ rainfall contour fits the dividing line very well.

The relationship between vegetation type and precipitation is also very close. The areas with annual precipitation less than $100 \mathrm{~mm}$ mainly consist of salt crust land, residual hills of wind erosion and sand dunes, and only in partial areas where the annual precipitation is more than $50 \mathrm{~mm}$ desert vegetation were developed, such as Tamarix spp., Nitraria tangutorum Bobr. and Lycium chinense Mill. In the middle layer where the annual precipitations are between $100 \mathrm{~mm}$ and $150 \mathrm{~mm}$, the dominant vegetation type is desert, but the vegetation coverage is higher than that in the inner layer. Because of the impact of high altitude, the distributions of vegetation in Qilian and Kunlun mountains are different from that of other middle-layer areas. In the outer layer of the basin, the annual precipitation is more than $150 \mathrm{~mm}$, and the vegetation consists of forests, mountain and valley shrubs, grasslands and various meadows. There are two main steppe types in the outer layer including Achnatherum splendens and desert steppe. Achnatherum splendens is widely distributed in the east of Dulan and the south of Ulan, while desert steppe is mainly distributed in the foothills of the southeastern margin of the basin. On the mountains where the annual precipitation is greater than $250 \mathrm{~mm}$, alpine grassland and alpine meadow are distributed. Shrub vegetation mostly consist of temperate deciduous broad-leaved shrubs of
Hippophae rhamnoides and Myricaria alopecuroides, which are widely distributed in floodplain and river terrace. The growth of forest is limited by precipitation and light, only in the mountains of the eastern margin of the basin, cold-resistant forest is distributed, which mainly consists of Picea crassifolia and Sabina przewalskii.

In summary, in the areas where the annual precipitation is less than $100 \mathrm{~mm}$, the corresponding value of $\overline{M_{N D V I}}$ is below 0.1 (except for the Xiangride Oasis). Qilian Mountains and Kunlun Mountains are the major components of the middle layer, and the values of $\overline{M_{N D V I}}$ are between 0.1 and 0.2 and the corresponding annual precipitation is between $100 \mathrm{~mm}$ and 250 $\mathrm{mm}$. The areas where the values of $\overline{M_{N D V I}}$ are greater than 0.2 are mainly located in the southeast of the basin with the annual precipitation $>150 \mathrm{~mm}$. In the areas where the values of $\overline{M_{N D V I}}$ are more than 0.3 , the corresponding annual precipitation is higher than $200 \mathrm{~mm}$, and in areas where the values of $\overline{M_{N D V I}}$ are more than 0.4 , the corresponding annual precipitation is higher than $250 \mathrm{~mm}$.

4.2.2 The relationship between vegetation distribution and runoff

The growth of vegetation in arid and semi-arid areas relies on topography and surface runoff, which has been manifested by the bright spots and linear feature in the interior of the basin. In order to further analyze the relationship between vegetation and runoff, we overlay Fig. 3 with the distribution map of stream systems in Qaidam Basin. The result shows that water bodies such as Tuosu Lake, Keluke Lake, Sugan Lake and Gasile Lake exist in the areas around all bright spots of NDVI. Generally, the areas of these bright spots generated by lakes are relatively small. Bright spots with large areas are mainly produced by many wetlands that are composed of rivers and groundwater outflow. For example, the three bright spots located in Wutumeiren, Golmud and Xiangride Oases in the central and southern parts of the basin are most distinct. The three bright spots are connected with each other through the linear feature, which is formed by the overflow zone of springs.

The rivers, lakes and groundwater outflow changed the moisture conditions, which makes the vegetation 
type in these areas different from that in other areas. In the interior of the basin desert vegetation is the dominant vegetation. However, in the areas around these water bodies reed and Kalidium are mainly developed in salt meadow. In the east of Golmud Oasis dense shrubs are even developed with relatively high $\overline{M_{N D V I}}$ values. In general, the existence of water bodies decreased the impact of precipitation and resulted in the inconsistence between the distribution of NDVI and the amount of precipitation in these areas. Therefore, to the north of Tuosu Lake the $50 \mathrm{~mm}$ precipitation contour forms the dividing line of the two sub-areas of inner layer, while to the south the $25 \mathrm{~mm}$ precipitation contour fits the dividing line well.

From the above analysis, we concluded that in the interior of the basin where the annual precipitation is less than $100 \mathrm{~mm}$ the pattern of vegetation distribution was mainly determined by the distribution of various water bodies. The $\overline{M_{N D V I}}$ values of these areas are significantly higher than that of the surrounding areas and have a ring structure. The vegetation types of these areas are also different from the vegetation controlled by precipitation and mainly consist of various salt meadows. In the areas where the annual precipitation is more than $100 \mathrm{~mm}$, the existence of water bodies has also improved the value of $\overline{M_{N D V I}}$, but the result is not as clear as the former.

\subsubsection{The relationship between vegetation distribution and altitude}

When describing the spatial distribution of NDVI, we mentioned that Tanggewula and other mountains constituted the boundary of NDVI distribution, which partly manifested the relationship between vegetation distribution and altitude. Fig. 6 is the topography map of Qaidam Basin. Through overlay analysis the impact of altitude on vegetation is mainly reflected in the following two aspects. The aspect is the effect of topography on the climate characteristics of Qaidam Basin. Qaidam Basin is surrounded by many high mountains, while the altitude in the interior of the basin is relatively low. The closed terrain structure seriously hinders the warm and moist air from the southeast and southwest reaching to the interior of the basin (Fig. 6). Therefore, the distribution of precipitation is very uneven in Qaidam Baisn which affects the distribution of vegetation greatly. Sub-area 1 is mainly composed of the low-altitude areas in the interior of the basin, where the altitude ranges from $2,676 \mathrm{~m}$ to $3,000 \mathrm{~m}$. Sub-area 2 has a certain corresponding relationship with the areas in the central and western parts of the basin, where the altitudes range from $3,000 \mathrm{~m}$ to 3,500 $\mathrm{m}$. The $\overline{M_{N D V I}}$ values of the mountains' surrounding areas are relatively high, most of which are more than 0.2. Among these mountains, Qilian Mountains and Kunlun Mountains are the major components of the middle layer and occupy an area of about $75 \%$ of the middle layer, while the mountains to the east of Tanggewula Mountains are the major part of the outer layer and occupy an area of about $70 \%$ in the outer layer. The second is the uplift effect of the mountains on precipitation, and the vertical gradient effect of temperature forms different combinations of water and heat. Therefore, the spatial variation of NDVI distribution in the surrounding mountains is significantly more intense than that in the interior of the basin, and is of obvious vertical differentiation characteristics. Specifically, in the lower part of the mountains where the altitudes are between $3,450 \mathrm{~m}$ and 3,950 $\mathrm{m}$, desert grassland plants such as Achnatherum and desert steppe are mainly distributed. Alpine grassland is mainly located in the rainy areas with the altitude more than 4,000 m. On Qilian Mountains where the altitude ranges from $3,800 \mathrm{~m}$ to $4,200 \mathrm{~m}$ and on Kunlun Mountains where the altitude ranges from $4,000 \mathrm{~m}$ to $4,500 \mathrm{~m}$, alpine meadow plants are mainly distributed such as Humilis and Elymus. In the higher part of the mountains where the altitude is more than $4,500 \mathrm{~m}$, alpine sparse vegetation is the major vegetation type.

4.2.4 The relationship between vegetation distribution and human activities

With the economic development of Qaidam Basin, the influence of human activities on vegetation distribution can not be ignored. However, the effect of human activities is mainly reflected by the dynamic change of vegetation, while the primary data used in this paper are the average annual maximum NDVI, which was hardly manifested the impact of human activities in specific period. Therefore, the relationship between vegetation distribution and human activities in Qaidam Basin was analyzed by the perspective of land use. The arable land of Qaidam Basin is mainly located in 


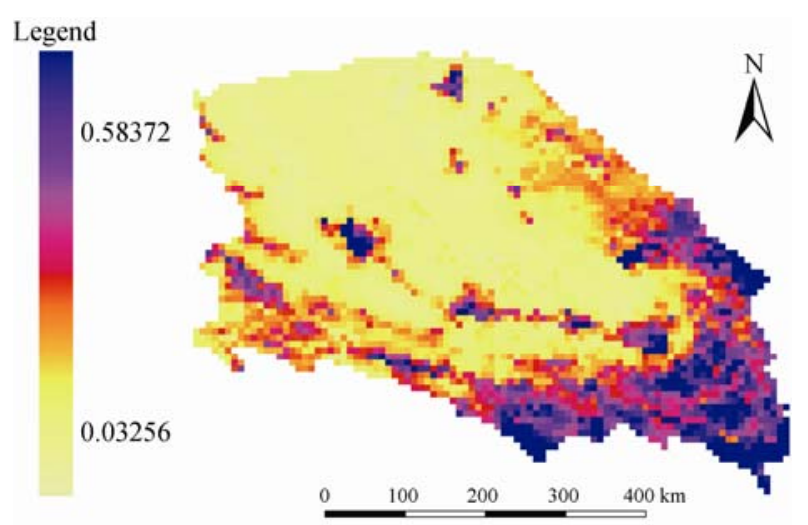

Fig. 2 Spatial distribution of $\overline{M_{N D V l}}$ in Qaidam Baisn

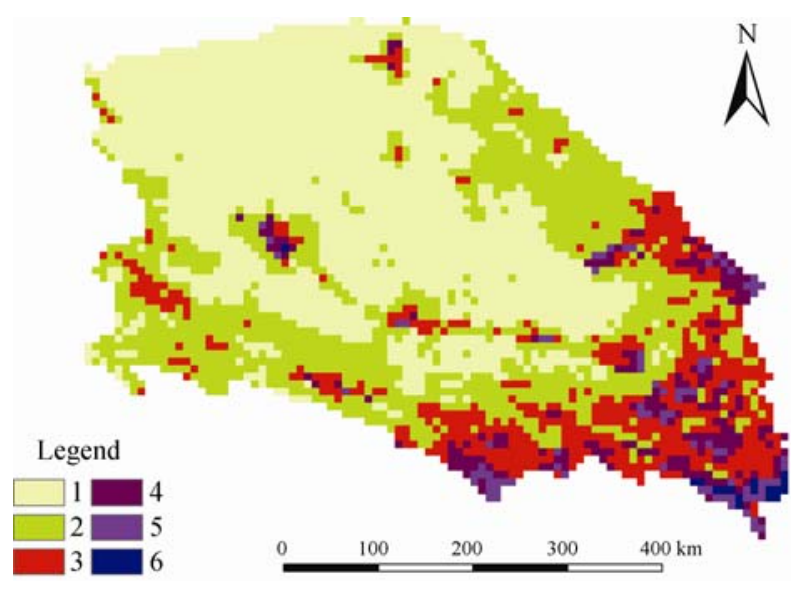

Fig. 3 Classification of $\overline{M_{N D V l}}$ in Qaidam Basin

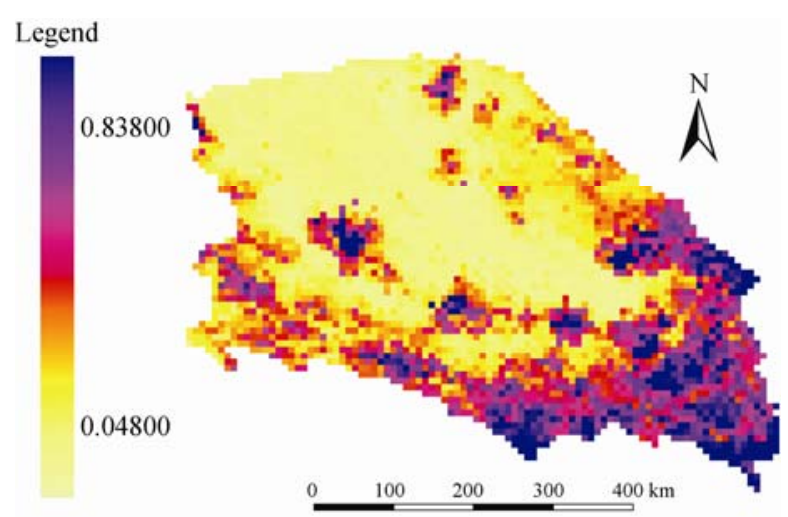

Fig. 4 Spatial distribution of $M_{N D V I}$ in Qaidam Basin

the lower reaches of Xiangride River, Nuomuhong River, Chahanwusu River, Xiariha River, Shaliu River, Dulansi River, Bayinguole River and Golmud River (Zhang and Jia, 1998), which constitutes the irrigated agriculture oasis of the basin. Therefore, the $\overline{M_{N D V I}}$

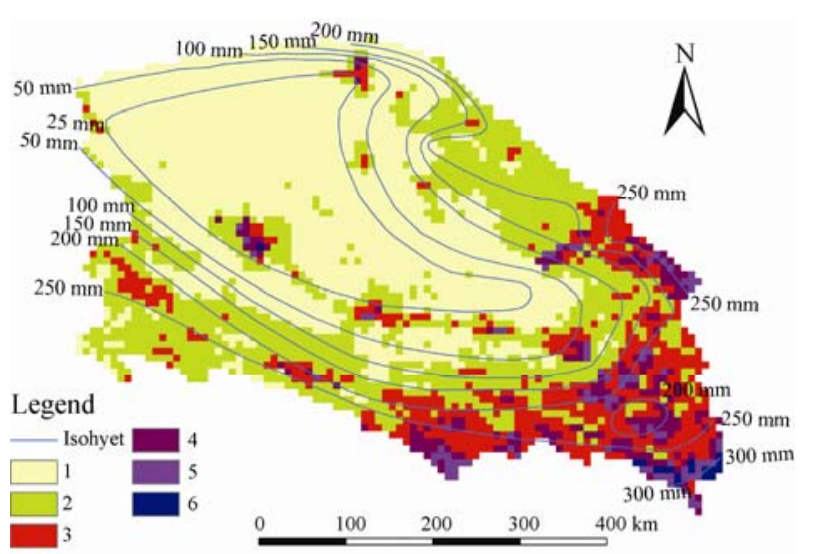

Fig. 5 Isogram of precipitation in Qaidam Basin

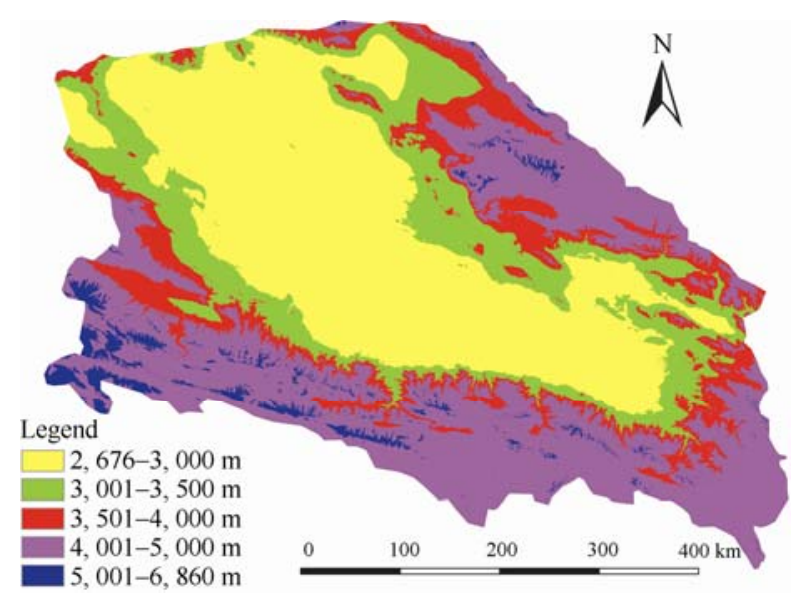

Fig. 6 Topographty map of Qaidam Basin

values of these areas are above 0.1 and higher than that of the surrounding areas. The oasis in Qaidam Basin can be divided into two categories. Xiangride Oasis mainly located in the opening of mountains is the typical one. The vegetation type of the area is mainly various desert ones. Therefore, although the annual precipitation of Xiangride Oasis is less than $100 \mathrm{~mm}$, the value of $\overline{M_{N D V I}}$ is above 0.1 and constitutes the part of the middle layer. Golmud Oasis located in the plain zone of fine soil is another category. Because of the blocking effect of fine soil on groundwater, groundwater outflow occurs. Therefore, the $\overline{M_{N D V I}}$ values of these areas are high. As a result, the pixels of these areas mix with the pixels of their surrounding areas and constitute bright spots and linear feature in the central and southern parts of the ba$\sin$ (Fig. 2). 


\section{Conclusions}

This study investigated the spatial distribution of vegetation in Qaidam Basin based on a long-time series of AVHRR/NDVI image from 1982 to 2006. Combined with the data of the precipitation, terrain, stream systems, and land use, and vegetation distribution map in Qaidam Basin, the factors that affect the spatial distribution of vegetation coverage through overlay analysis were further studied. The conclusions are as follows:

(1) The vegetation coverage is generally low in Qaidam Basin. The $\overline{M_{N D V I}}$ values range from 0.0326 to 0.5837 , and the average is only 0.1404 . The spatial distribution of $\overline{M_{N D V I}}$ has a three-layer semiring structure. The outer layer is mainly located in southeast of the basin, which is surrounded by Qilian Mountains and Tanggewula Mountains. The $\overline{M_{N D V I}}$ values of this layer ranges from 0.2 to 0.6 . Qilian and Kunlun mountains are the major components of the middle layer, and the $\overline{M_{N D V I}}$ values are between 0.1 and 0.2. The areas in the central and west parts of the basin where the values of $\overline{M_{N D V I}}$ are less than 0.1 , constitute the inner layer, which can be divided into two sub-areas further. The existence of the rivers, lakes and groundwater outflow makes this semi-ring structure present non-continuous state in partial areas, and forms prominent bright spots and linear features.

(2) The influencing factors of vegetation distribution in Qaidam Basin include precipitation, runoff, altitude and human activities. Precipitation has a correlation with altitude, and the two factors together determine the basic pattern of vegetation distribution in Qaidam Basin. The effect of runoff and human activities is mainly reflected in partial areas, and often breaks the distribution pattern of vegetation controlled by precipitation and altitude.

(3) There is a good corresponding relationship between precipitation contours and semi-ring structure of vegetation. The boundary between the inner and mid-

\section{References}

Chen S P, Tong Q X, Guo H D. 1998. Study on Mechanism of Remote

Sensing. Beijing: Beijing Publishing House.

Cheng Y, Xu D X, Guo N. 2008. Analysis on the vegetation change in the dle layers is consistent with $100 \mathrm{~mm}$ precipitation contour and the boundary between middle and outer layer is almost completely consistent with $150 \mathrm{~mm}$ precipitation contour. Because of the existence of groundwater outflow in the center and south of the basin, the boundary between sub-areas 1 and 2 is different from the south and north of Tuosu Lake. To the north of Tuosu Lake $50 \mathrm{~mm}$ precipitation contour forms the dividing line of the two sub-areas, while to the south $25 \mathrm{~mm}$ precipitation contour fits the dividing line very well.

(4) The impact of water bodies on vegetation distribution is manifested by the change of the moisture conditions in their surrounding areas. The existence of the rivers, lakes and groundwater outflow breaks the distribution pattern of vegetation controlled by precipitation and forms bright spots and linear features of NDVI. The spatial distribution of $\overline{M_{N D V I}}$ around these water bodies has a concentric circle, and the values of $\overline{M_{N D V I}}$ decrease with the increase of the distance from these water bodies.

(5) The effect of topography on vegetation distribution is relatively complex, which works primarily through its influence on climate, especially on precipitation and temperature. This effect, on one hand, intensifies the spatial variation of vegetation distribution, on the other hand, forms the vertical differentiation characteristics of vegetation in Qaidam Basin.

(6) The impact of human activities on vegetation is mainly reflected in agricultural oasis area which makes the vegetation type and coverage of these areas differ from other areas that are decided by precipitation, and increases the value of $\overline{M_{N D V I}}$ overall.

\section{Acknowledgements}

This research was supported by the National Natural Sciences Foundation of China $(90302009,40801216)$ and the Ministry of Water Resources' Special Funds for Scientific Research on Public Causes (201001062). Thanks are given for their data support to Global Inventory Monitoring and Modeling Studies (GIMMS), and United States Geological Survey (USGS).

Qilian Mountains since recent 22 years. Arid Zone Research, 25(6): $772-777$.

Chu D, Dejiyangzong, Pubuciren, et al. 2007. The response of typical 
vegetation growth to climate conditions in north Tibetan Plateau. Journal of Applied Meteorological Science, 18 (6): 832-838.

Cui L L, Shi J, Yang Y M, et al. 2009. Ten-day response of vegetation NDVI to the variation of temperature and precipitation in eastern China. Acta Geographica Sinica, 64 (7): 850-860.

Fan G X, Zhao J G. 2008. Analysis on ecological environment protection and construction of Qaidam Basin. Research of Qaidam Development, 1: 16-19.

Guo Z X, Wang Z M, Song K S, et al. 2007. Correlations between forest vegetation NDVI and water/thermal condition in Northeast China forest regions in 1982-2003. Chinese Journal of Ecology, 26(12): 1930-1936.

Han X Z, Li S M, Luo J N, et al. 2008. Study on spatiotemporal change of vegetation in China since 20 years. Arid Zone Research, 25(6): $753-758$

Hope A, Boynton W, Stow D, et al. 2003. Inter-annual growth dynamics of vegetation in the Kuparuk River watershed based on the normalized difference vegetation index. International Journal of Remote Sensing, 24(17): 3413-3425.

Justice C O, Hiernaux P H Y. 1986. Monitoring the grasslands of the Sahel using NOAA AVHRR data: Niger 1983. International Journal of Remote Sensing, 7: 1475-1497.

Li D L, Mu Y Q, Ma X H. 2009. The application of ETM data in the survey of ecological environment factors of Qaidam Basin. West-China Exploration Engineering, 2: 88-91.

Liu Y H. 2000. Rational Utilization of Water Resources and Ecological Eenvironment Protection of Qaidam Basin. Beijing: Science Press, $1-20$.

Ma J F, Lv C H, Wang Q. 2008. Land-cover classification of the Qaidam Basin based on MODIS NDVI time series data. Arid Land Geography, 31(3): 442-448.

Ma M G, Dong L X, Wang X M. 2003. Study on the dynamically monitoring and simulating the vegetation cover in Northwest China in the past 21 years. Journal of Glaciology and Geocryology, 25 (2): 232-236.

Nicholson S E, Farrar F J. 1994. The influence of soil type on the relationships between NDVI, rainfall, and soil moisture in semiarid Botswana: NDVI response to rainfall. Remote Sensing of Environment, 50: 107-120.

Rasmusen M S. 1998. Developing simple, operational consistent
NDVI-vegetation models by applying environmental and climatic information: part II. crop yield assessment. International Journal of Remote Sensing, 19: 119-139.

Ren H Y. 2007. Remote sensing analysis on ecological environment factors of Qaidam Basin. Research of Qinghai Land, 5: 32-35.

Richard Y, Poccard I A. 1998. Statistical study of NDVI sensitivity to seasonal and interannual rainfall variations in Southern Africa. International Journal of Remote Sensing, 19: 2907-2920.

Song Y, Ma M G. 2007. Study on vegetation cover change in Northwest China based on SPOT VEGETATION data. Journal of Desert Research, 27(1): 89-93.

Stow D, Hope A, McGuire D, et al. 2004. Remote sensing of vegetation and land-cover change in Arctic Tundra Ecosystems. Remote Sensing of Environment, 89: 281-308.

Tucker C J, Townshend R G, Goff T E. 1985. African land-cover classification using satellite data. Science, 227: 369-375.

Yang X W, Zhou H M, Li J, et al. 1998. Feasibility research on estimating global paddy yield using remote sensing. Quarterly Journal of Applied Meteorology, 9(2): 251-256.

Yu H Y, Zhang Z D, Zhang P M. 2007. RS- and GIS-based evaluation and dynamic monitoring of land desertification in Qinghai Province. Arid Zone Research, 24 (2): 153-158.

Zhang H X, Jia S F. 1998. Rational land utilization and sustainable oases ecological agriculture development of the Qaidam Basin. Journal of Arid Land Resources and Environment, 12 (4): 44-54.

Zhang X X, Ge Q S, Zheng J Y. 2005. Impacts and lags of global warming on vegetation in Beijing for the last 50 years based on remotely sensed data and phonological information. Chinese Journal of Ecology, 24(2): 123-130.

Zhao C C, Hu H, Dong X, et al. 2009. Evaluation on ecological security of desertification in Chaidamu Basin. Forest Inventory and Planning, 34 (4): 22-25.

Zhao J, Jiang Q G, Li W D, et al. 2008. Study on evolutionary regionalization of ecological environment in source regions of the three rivers based on changes of NDVI. Global Geology, 27(4): 427-431.

Zhao Y S. 2003. Principles and Methods of Analysis of Remote Sensing Applications. Beijing: Beijing Publishing House, 366-375.

Zheng Z J, Liu Y J, Zhang B C. 2004. Improved remote sense monitoring on snow cover of China in winter. Journal of Applied Meteorological Science, 15 (Suppl.): 75-84. 